\title{
Sexualidade e Educação: fundamentos políticos e possibilidades pedagógicas
}

Michele Fachini

Mestranda em Educação pela UNICAMP

\section{Resumo}

O ensaio investiga a dimensão histórica da sexualidade no Ocidente e destaca as etapas de produção de referenciais hegemônicos para as vivências e representações dos saberes sobre Sexo e Sexualidade. Destaca algumas interpretações políticas e éticas desses modelos históricos e suas derivações comportamentais e educacionais. Aponta possibilidades de abordagens da Educação Sexual na escola, com propostas de sensibilização de crianças e adolescentes para a compreensão positiva e humanista dessa dimensão. Define a concepção de Educação Sexual Emancipatória.

Palavras-chave: Sexualidade; Educação; Escola.

\begin{abstract}
The essay investigates the historical dimension of sexuality in the West and highlights the stages of production of hegemonic references to the experiences and representations of knowledge about sex and sexuality. Highlights some ethical and political interpretations of historical models and their derivations behavioral and educational. Points possible approaches to sex education in school, with proposals to raise awareness of children and adolescents to understand that positive, humanistic dimension. Defines the concept of Sex Education Emancipation.
\end{abstract}

Keywords: Sexuality; Education; Emancipation; School. 


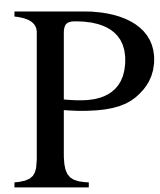

retendemos debater nesse artigo a importância histórica da dimensão da Sexualidade para o entendimento da condição humana, pessoal e coletiva. E buscaremos demonstrar que esse teme é um genuíno tema da Filosofia. Ao final encaminharemos algumas propostas de produção de referenciais educacionais para a atuação escolar no campo da sexualidade e educação sexual, de modo a configurar algumas diretrizes para uma política de abordagem da sexualidade na escola.

A busca de compreender a si mesmo é uma distinção humana. Desde Sócrates (469-399 a.C.) que inaugura a filosofia clássica, a Filosofia tem se preocupado com a significação da natureza humana. Já antes desse autor paradigmático a Filosofia procurava explicar a origem do mundo balizada nas observações da natureza e a atitude socrática colocou a filosofia na temática da formação do homem. Sócrates concebia o homem como resultante da união de dois elementos dois princípios alma (ou espírito) e corpo. Esse dualismo marcará toda a tradição ontológica ocidental.

Conhecer e definir a condição humana é a tarefa primordial da Filosofia a partir de Sócrates de da polis grega. A definição mais clássica de homem é a expressão de Aristóteles (384-322 a.C.) o homem é essencialmente um animal político. Era própria daquela época a atitude de buscar obter definições mais precisas sobre o ser das coisas recorrendo a uma espécie de fórmula: definição (=) gênero próximo (+) diferença específica. Assim encaixavam suas ideias e construíam suas proposições de gênero, tomadas como universais e unilaterais. Aristóteles usou o gênero próximo, o homem, e a diferenciação da dimensão social e política. Platão (427-347 a.C.) entre as tantas definições que deu sobre a condição humana, da alma eterna ao corpo sensível, igualmente definiu o Homem como um bípede implume, destacando como gênero a condição de bípede, duas pernas, e marcava a dimensão da diferença na característica de ser implume, por não ter penas. João Pessoa (1888-1935), um grande poeta português, formulou uma definição tecnicamente mais precisa, mas igualmente acidental, embora mais dramática: o Homem é um cadáver adiado! 
Os pesquisadores do tema definido como "sexualidade" sofreram pressões política, sociais e culturais, no transcorrer dos tempos e épocas históricas recentes. A pesquisa científica no campo da sexualidade teve seu início na Europa, nos países anglo-saxões e germânicos, destacando-se o pioneirismo dos trabalhos de Krafft-Ebing (1886), de Havelock Ellis (18961928), de Magnus Hirschefeld (1930) que fundou o Instituto de Sexologia de Berlin, além de Sigmund Freud (1950, apud Nunes, 1996). A repercussão desses estudos avançou internacionalmente na primeira metade do século $\mathrm{XX}$, inclusive nos Estados Unidos, com pesquisas de natureza demográficas e quantitativas, como os estudos que criticavam o conservadorismo, como o trabalho de Kinsey (1948) que analisava diferentes aspectos do comportamento sexual e os fatores que poderiam explicá-los. As normas socioculturais dificultaram muito os trabalhos dos pesquisadores pioneiros como o casal Master e Johnson (1968), pesquisadores singulares das reações sexuais humanas que, com muita ousadia e coragem, apesar dos entraves, puderam contribuir para o conhecimento do "por quê" de tal ou tal cristalização do desejo, suas vias de realização do cotidiano do sujeito, além de questionar algumas ideias clássicas sobre a sexualidade feminina.

Os trabalhos sobre sexualidade humana sob perspectivas de diferentes disciplinas, permeando a Biologia, a Medicina, a antropologia, a Sociologia, a Psicanálise e a Psicologia puderam contribuir para essa reconstrução crítica da sexualidade humana até chegarmos à consideração de uma forma primordial de expressão dessa identidade sexual humana através da descoberta da sexualidade da criança, efetuada por S. Freud.

Um destacado pesquisador referencial do campo da sexualidade humana no século XX é Michel Foucault (1926-1984) que, diante da perspectiva filosófica e histórica que assume em seu método, afirma a originalidade burguesa dos estudos e prescrições sobre conduta sexual a partir do século XVIII. Em cada época as relações sociais e as políticas hegemônicas nas sociedades produziram normas e representações sobre sexualidade. 
O autor Nunes (1987) diz,
A análise da evolução histórica e cultural de uma forma dialética permite-nos perceber as diferentes transformações das sociedades humanas do passado e as perspectivas que abrem para o futuro. A categoria fundamental é a do processo. As mesmas categorias permitem relativizar os padrões sociais de normatização da sexualidade bem como compreender sua precariedade e seus interesses, além de evidenciar os mecanismos de controle e constituição da chamada “normalidade” sexual. (NUNES, 1987, p. 52.)

Se tomarmos o homem como produto de relações sociais em diferentes períodos e etapas históricas, necessariamente teremos que assumir a sexualidade igualmente como uma produção de épocas e significados históricos. De acordo com os estudos de NUNES (1996), são cinco etapas de compreensão da sexualidade, relacionando-as ao mundo ocidental e seu andamento histórico.

A etapa inicial será definida como aquela que continha uma compreensão mítica e matriarcal da sexualidade. Para começar, cabe um olhar com lente ampliada, pois as sociedades foram se construindo e caracterizando a sexualidade nesse contexto, o termo mítico aqui apresentado se remete à civilização nos períodos Paleolítico Inferior (30 mil a 10 mil a.C.) e Superior (10 mil a 4 mil a.C.). Nesse período o homem dispunha do seu tempo material com atividades e processos de sobrevivência voltados à caça, pesca, coleta de frutos e raízes, utilizando machados e outros utensílios denominados de lavra desenvolvidos entre a era da pedra lascada e da pedra polida.

Tal sociedade se caracterizava, para o historiador Campos (1981), dessa maneira:

As comunidades do Paleolítico possuíam certo grau de sedentarização, mas também viviam se deslocando em perseguição aos animais que caçavam. Necessidade da colaboração, principalmente por os grandes empreendimentos de caça, deve ter gerado, no final do período, o aparecimento dos primeiros clãs, famílias extensas onde várias gerações se sobrepõem. Os clãs do Paleolítico eram matriarcais, uma vez que os homens, em sua atividade de caçar, viviam se 
deslocando mais constantemente, deixando às mulheres toda e qualquer forma de governo familiar. (CAMPOS, 1981, p.58, apud Nunes).

E, ainda para Nunes (1987) “O Paleolítico é todo ele predominantemente dominado pelo matriarcalismo, isto é, pela valorização e pelo culto ao elemento feminino, materno, procriador e organizador da sociedade primitiva”. (NUNES, 1987, p. 58). Nesse período, na sociedade primitiva, a mulher apresentava os papéis de mãe e organizadora, mas diante da sexualidade cabe destacar o aparecimento do culto à fertilidade, a mulher detinha essa função plena de procriar, que era tida como força mítica, por isso engendrava relativo poder e explicava a concepção desta etapa como mítica. Apesar das mulheres deterem o controle do poder familiar e o controle da organização social por vários milhares de anos, o período seguinte, o Neolítico, iniciado por volta de nove mil a.C., diante das alterações nas condições materiais e climáticas, além da descoberta da pedra polida e do crescente avanço da população, registraria as condições de radicais mudanças nas formas de exercício do poder.

Nunes (1987) expressa que teria sido no período Neolítico o aparecimento das primeiras formas de religião e de poder patriarcal, isto é, dominado pelo homem e pela simbolização, política e religioso, de sua função de pai ou chefe.

\begin{abstract}
...surgem as primeiras grandes culturas de trigo, cevada, arroz, milho, mandioca. A Agricultura é o fator fundamental de subsistência e também de certa forma a propriedade da terra. Os homens logo controlam o poder real, os exércitos e as formas de defesa, luta e guerra, e o poder ideológico, a religião, assumindo as funções religiosas, mágicas e sacerdotais. É nessa passagem que muitas sociedades há a submissão da mulher e sua semi-escravização cultural. As funções da mulher são usurpadas pelos homens e em decorrência surgem às representações simbólicas do poder masculino, os deuses são machos, as leis, funções e organização militar e religiosa são privilégios exclusivos do homem. (NUNES, 1987, p. 60).
\end{abstract}

A segunda etapa é marcada pela construção e hegemonia do modelo patriarcal, projetado na linha do tempo, referindo-se à sociedade grega, por volta dos 5000 a.C. Se formos considerar as contraposições desse modelo, 
mencionando os papéis de gênero, compreenderemos que nesse período amplo dá-se uma radical mudança ou inversão, o homem detém a posição de poder sobre a mulher, os interesses sociais e econômicos antes femininos passam a ser relevantes agora para o exercício do mando masculino. A expressão máxima dessa guinada é o casamento, base da unidade familiar, já no avançado tempo dos grandes impérios bélicos clássicos da Antiguidade: nessas sociedades patriarcais o casamento era um contrato social e econômico, pautado no direito patriarcal, tal como descreve Nunes (1987).

O Homem é agora o senhor e primeiro patriarca, exigente de fidelidade exclusiva e juiz implacável. A mulher é inferiorizada, impura, não participa do sacerdócio, exclusivamente masculino, nem freqüente o centro e templo. A mulher pertencia ao marido e estava proibida de outras relações sexuais, mas o marido era livre e senhor de sua conduta, não havia sanções sociais que o impedissem de ter outras relações hétero e homossexuais fora de sua casa. (NUNES, 1987, p. 68)

Pode-se considerar que há raízes desse modelo presentes ainda hoje em nossa sociedade e a relação entre sexo e sexualidade é reforçada pelo machismo, que distancia a igualdade dos sexos, reforça os estereótipos sexuais dominantes e parece querer congelar os papéis sexuais tradicionais, tomados como universais e eternos.

A terceira etapa da constituição da sexualidade será conhecida como época da chamada civilização cristã, época cristã, na qual triunfa a ideologia do Cristianismo e de sua visão de mundo. A imposição da tradição judaicocristã, através da aculturação produzida pelas concepções presentes nas Escrituras e nos livros considerados sagrados do Antigo e do Novo testamento, foi usada para transformar radicalmente as concepções e sistemas de relações e significados. Estes livros eram seguidos por quase todas as religiões, cabe salientar a visão de Santo Agostinho para a sexualidade, nesse autor modelar e referencial para a Cristandade ela é vista como uma qualidade má, fruto do pecado do homem, o casamento tem o fim único de procriação e todo ato sexual é pecaminoso. Segundo o estudioso brasileiro, 
(...) na idade Média, podemos dizer que não havia ainda um total controla da sexualidade. Entre as classes populares proliferaram as relações primárias, comunitárias. As casas não tinham quartos separados entre homens e mulheres. A linguagem da sexualidade era rica e picante, músicas, piadas, formas de expressão. Todo esforço da igreja não fora capaz de enquadrar o materialismo das camadas populares. (NUNES, 1987, p. 87)

Essa etapa é marcada pelo Cristianismo emergente do qual deriva a moral sexual medieval, que foi a base da doutrina moral cristã pregada por Santo Agostinho, que negava a sexualidade como força positiva ou natural. Toda a tradição da Patrística, a partir da pastoral da carne e do conceito de pecado se expande sobre as culturas dos povos cristianizados, tornando-se a base da visão de mundo europeia e depois, ocidental de um modo geral. A idade média (sec. V- sec. XVI) terá diferentes versões, algumas cumulativas, dessa concepção de sexo e sexualidade como pecaminosas, abominação e sinal de perdição!

A quarta etapa está ligada às transformações do mundo medieval, no campo da sexualidade há grandes mudanças com o fim do mundo medieval, a reforma de Lutero abala a Igreja e reúne as condições matriciais para fundamentar a moral sexual moderna que, no dizer de Nunes (1987),

(...) a pedagogia e a moral luterana começam a mapear o corpo, reduzindo a sexualidade a um isolamento e a uma negatividade assustadores. A nudez, que naquela época era vista com naturalidade, começa a ser coberta de pano e conceitos. A linguagem sobre o sexo passa a ser controlada, e nos livros tudo o que trata do sexo é expurgado. O sexo é o grande inimigo do trabalho, agora a nova forma de compreender o homem. (NUNES, 1987, p. 92)

A expansão e exigência da confissão tridentina era outra forma de contenção, visava gerar o poder sobre a consciência das pessoas, principalmente no que se referia a questões sexuais. O sexo era interditado como forma de prazer, condenado e proibido, tinha a função única da procriação, constituindo as bases da sexualidade reprimida ocidental. Podese destacar nesta etapa que a redução do sexo à função estrita de procriação obedecia a critérios de interesses econômicos e políticos de bastidores: 
preparar a massa de trabalhadores, proletários, que tem sua etimologia no conceito de prole, muitos filhos, para abastecer as novas máquinas da sociedade industrial. A masturbação é tratada como "doença” na iconografia da repressão, manifesta-se nesse momento o sentimento de vergonha e de pecado, de desvio e perversão, sobre o sexo. Se formos localizar o modelo ou núcleo dessa representação de sexo e sexualidade na sociedade esse seria identificado como o auge da Era Vitoriana, o século XVIII e sua genética produção do capitalismo industrial e urbano.

A quinta etapa caracteriza-se por propor algumas mudanças, ainda que possam ser quantitativas e circunstanciais, conectadas com a crise do capitalismo no século XX e a perda da hegemonia europeia sobre o mundo. Com o surgimento da sociedade do consumo, o mundo capitalista passa a absorver as mudanças que conduziram o movimento repressivo da sexualidade durante séculos, nesse momento começam a se modificar o sentido do sexo e de suas práticas, articuladas pelas ações dos novos interlocutores da sexualidade oficial, a saber: os médicos e os saberes da medicina e biologia! Essa alteração de sentidos provoca igualmente transformações sociais na esfera da moral, da mercantilização do corpo e induz novas condutas, que passam a instigar a expressividade da sexualidade. O capitalismo norte-americano, no período pós Segunda Guerra Mundial, passa a estampar sua hegemonia sobre o mundo, alia-se aos interesses burgueses europeus e produz uma nova síntese de moral e representação sexual: a dessublimação compulsiva das massas e corpos. No entanto, mesmo nessa contradição, os direitos sexuais alavancaram as conquistas por seus espaços, seus novos papéis, tanto para o homem quanto para a mulher.

Atualmente o consumismo prolifera no ambiente em que vivemos e os meios de comunicação, em todas as suas formas, o rádio, a TV, a internet, o jornal, as muitas revistas, entre outros, as redes sociais, parecem centrar sua ação na busca dos proveitos mercantis dessa exibição industrial e mecânica da sexualidade, principalmente as mídias de manejo de massa que influenciam diretamente a sociedade utilizando esse espaço também para 
moldar e explorar a sexualidade. Para Nunes (1987) esse modelo se define como mercantilista e exploratório de uma sexualidade consumista,

(...) a sexualidade numa dimensão emancipatória supõe também normas e limites como marcos de sujeitos plenos, e não sanções, preconceitos, segregações, um desfiar de acusações, pecados e medos....A normatização equilibrada e tolerante, o cuidado de si, a temperança nos assuntos do desejo recusam a anomia e a heteronomia parciais e propõe a busca coerente da autonomia e equilibrado conceito de compreender as contradições e superá-las dinâmica, arbitrária e dramaticamente no cotidiano, nas condições reais de nosso viver. Ao mesmo tempo é fundamental importância destacar a crítica à sexualidade consumista, está sim também desumanizadora, reduzindo corpos e pessoas a um conjunto de experiências vorazes, ao mesmo tempo frustrantes e compensatórias de grandes ausências de sentido.

Ao retomar as vivências sexuais abertas e considerar a proposta de uma possível antropologia do prazer, confiante e transparente, bem como a definição de uma expressão possível do desejo comedido e profundo que açambarca a sexualidade teremos que pensar na superação dessas morais históricas, superpostas e consequentes, combinadas entre si para produzir submissão e controle, na lógica do capital. Será preciso conceber a vivencia da sexualidade sem os receios e sem as máscaras da cotidianidade massacrante, de violência simbólica inibidora, do simulacro da impessoalidade e da mercadorização do corpo. É nessa direção que o homem (Nunes, 1987), ao retomar fundamentos éticos e constituintes políticos de condutas emancipatórias para a sexualidade, realizar-se-á como ser que produz o sentido de sua vida, de suas ações e de sua história.

A sexualidade é uma dimensão humana fundamental, que não pode jamais ser negada ou anulassem deixar seqüelas éticas e privações existenciais, nenhuma sublimação de poder compensar o fracasso sexual, nem estético, nem econômico, pois a sexualidade é a dimensão híbrida do desejo e da sociedade, dos afetos, e paixões, das realizações e incompletudes emancipatórias, talvez uma das mais claras das utopias existenciais e políticas (NUNES, 1987, p. 125-126).

Tal é nossa esperança, a de compreender e encaminhar a compreensão da Sexualidade como uma força subjetiva e social de emancipação, como 
diretriz para novas perspectivas de felicidade e de sustentabilidade para todas as formas de vida. A Organização Mundial de Saúde (OMS, 1975) define como:

A Sexualidade Humana forma parte integral da personalidade de cada um. É uma necessidade básica e um aspecto do ser humano que não pode ser separado de outros aspectos da vida. A sexualidade não é sinônimo de coito e não se limita à presença ou não do orgasmo. Sexualidade é muito mais do que isso. É energia que motiva encontrar o amor, contato e intimidade e se expressa na forma de sentir, nos movimentos das pessoas, e como estas tocam e são tocadas. A sexualidade influencia pensamento, sentimentos, ações e integrações, e portanto à saúde física e mental. Se saúde é um direito humano fundamental, a sexualidade, a saúde sexual também deveria ser considerada como direito humano básico. A saúde mental e a integração dos aspectos sociais, somáticos, intelectuais, emocionais de maneira tal que influenciem positivamente a personalidade, a capacidade de comunicação com outras pessoas e o amor.

Dessa concepção decorre a importância de nossa consideração da educação sexual das crianças. A sexualidade da criança deve ser considerada na educação, segundo os Parâmetros Curriculares Nacionais (1997), no volume Tema Transversal ‘Orientação Sexual’ volume 10, assim se expressa:

(...) Nessa exploração do próprio corpo, na observação do corpo dos outros, e a partir das relações familiares é que a criança se descobre num corpo assexuado de menino ou menina. Preocupa-se então mais intensamente com as diferenças entre os sexos, não só as anatômicas, mas também com todas as expressões que caracterizam o homem e a mulher. A construção do que é pertencer a um ou outro sexo se dá pelo tratamento diferenciado para meninos e meninas, inclusive nas expressões mais diretamente ligadas e pelos padrões são oriundos das representações sociais e culturais construídas a partir das diferenças biológicas dos sexos e transmitidas pela educação, o que atualmente recebe a denominação das relações de gênero. Essas representações absorvidas são referenciais fundamentais para a constituição da identidade da criança.” (BRASIL,1997,p.118)

Para adentrar um pouco mais, Castro e Silva, autor que fundou em 1984 o Programa de Orientação Sexual na Educação na Prefeitura 
Municipal de Campinas, no contexto de escola enquanto local de vivência da sexualidade, argumenta:

O aluno está na escola e nela vai passar grande parte de duas
etapas significativas da sua vida: a infância e a adolescência,
períodos em que a sexualidade se manifesta nas curiosidades,
nas dúvidas e nos relacionamentos vividos dentro e fora do
ambiente escolar, sendo parte do dia a dia do aluno. Esta mesma
sexualidade é, porém, muitas vezes, negada ou reconhecida de
uma forma inadequada pelo professor.(...É preciso, entretanto,
ver o aluno como ser humano, que significa, necessariamente,
vê-lo como indivíduo sexualizado, pois não há possibilidade de
haver humanidade sem sexualidade. Esta é inerente ao ser
humano e, se desejamos oferecer uma resposta a altura da
formação integral do aluno, temos que reconhecer e atender às
questões de sua sexualidade, porque este, antes de mais nada, é
um direito que lhe cabe.(...) Viver a sexualidade na escola
significa também para o aluno o prazer de estar como o outro,
nas conversas, nas trocas, nas atividades lúdicas, nas
discussões, nas seduções, paqueras, ou seja, nas aproximações
"possíveis”.(CASTRO,1995, p. 12).

Importante destacar os conceitos diferenciando o sexo da sexualidade, sob a comparação de Nunes (2000) a Sexualidade seria a essencial dimensão humana baseando-se nas características exclusivamente humanas de afetividade e erotismo. Não está secundarizada na condição humana, mas sim vinculada às demais habilidades e potencialidades, ela é uma marca única do homem presente na condição cultural e histórica do homem, este tudo que faz ou realiza envolve sua dimensão de ser sexuado. A Sexualidade é a própria vivência e significação do sexo, carrega dentro de si intencionalidade e escolha que a tornam dimensão humana, dialógica e cultural, enquanto o Sexo, ainda que constituído a partir da marca genital, o Sexo é marca biológica, caracterização genital e natural. Sexualidade, conceito cultural constituído pela qualidade de significação do Sexo”. (NUNES, 2000, p. 74).

As possibilidades pedagógicas reflexivas acerca da sexualidade pela música, percorrendo um caminho histórico e cultural da evolução sexual sob forma de canções da música popular brasileira, parecem fecundas e disparadoras de discussão na sala de aula. O jornalista e escritor Rodrigo 
Faour, autor da obra História Sexual da MPB: a evolução do amor e do sexo na canção brasileira contribui nesta temática.

(...) A nossa civilização ocidental digeriu ao longo de mais ou menos 2.500 anos (de 3100 a 600 a.C.) essa lógica patriarcal, que nasce no Ocidente com a democracia de Atenas, no século V a.C., e só começa a mudar por ocasião da Revolução Francesa que defendia a democracia aplicada a todos. Assim essa lógica virou sinônimo de normalidade, e foi aceita como tal, dado o apoio decisivo de duas forças: a religião (com o Cristianismo à frente) e a ciência. Todo imaginário ocidental demarcou por séculos a fio o papel da mulher como pessoa fraca, frágil, lenta de entendimento, emocionalmente instável, fútil, hipócrita e totalmente indigna de confiança. ... já o homem masculino, cujas características são: força, coragem, ousadia, desafio... ”(FAOUR, 2006, p. 94)

Além do mais para se tornar ativa a educação sexual fundamentalmente carece ser contextualizada numa Educação Sexual Emancipatória, o que propõe Nunes e Silva (2000) entendida como a formação para a compreensão plena, integral, histórica, ética, estética e psicossocialmente significativa e consciente das potencialidades sexuais humanas e de sua vivência subjetiva, socialmente responsável e realizadora. Trata-se da qualificação ontológica da sexualidade humana e sua construção ético-social.

Para isso, a Escola, instituição inserida na praxis social, e na consideração de seu papel indiscutível na formação de homens e mulheres omnilaterais, deveria assumir e Educação Sexual na esteira de formar pessoas capazes de apropriação plena da condição humana e inserção emancipadora no mundo do trabalho, da cultura e das vivências sexuais realizadoras.

Conforme aponta Reich (1977) seremos capazes de libertar nossa sexualidade enquanto educadores sexuais emancipados, na busca de promover possibilidades pedagógicas, quando conseguirmos nos permitir viver a exigência biológica de satisfação sexual natural, com sua sensibilização e simbologia intersubjetivas. Ou seja, essa transformação que atingimos, possibilitando a fusão do corpo e da mente, superando o duelo de 
racionalidade e instinto, permitindo-nos viver a plenitude da nossa sexualidade para a experimentação do momento sublime da sexualidade, atingindo nossa potencialidade orgástica, na qual a vida escorre de dentro para fora, fruição e renascimento dialético entre viver e morrer: em um momento parece que perdemos todas as energias do corpo, mas em outro nos vemos plenos de forças, pois se inunda a alma de vida. Esperamos que essas diretrizes éticas e estéticas possam ser proposições fecundas para consolidar e embasar novas políticas de educação e formação para a sexualidade emancipatória!

\section{Referências Bibliográficas}

BRASIL, Secretaria de educação Fundamental. Parâmetros Curriculares Nacionais: Pluralidade Cultural, Orientação Sexual / Secretaria da Educação Fundamental Brasília: MEC/SEF, 1997.

CASTRO e SILVA, Ricardo. Orientação Sexual vivida por educadores e alunos: possibilidades de mudanças. Dissertação Mestrado - Universidade Estadual de Campinas- Campinas- 1995.

FACHINI, A. Michele. Educação Sexual e Escola: trajetórias e trilhas para além da orientação transversal - Um estudo interpretativo do programa de Orientação Sexual nas Séries Iniciais de Campinas - SP. Trabalho Conclusão Curso- Faculdade Educação- Universidade Estadual de Campinas, 2007.

FAOUR, Rodrigo. História Sexual da MPB: evolução do amor e do sexo na canção brasileira/ Rodrigo Faour. - Rio de Janeiro: Record, 2006.

FREUD, S. Uma teoria sexual. In: Obras Completas, Madrid: Nueva Editorial, $1967^{\mathrm{a}}$. (v.1.771-817.)

FOUCAULT, Michel. Vigiar e punir. Petrópolis, Vozes. 1977

NUNES, A. César. Desvendando a sexualidade/ César Aparecido NunesCampinas, SP: Papirus, 1987.

- Aprendendo Filosofial César Aparecido Nunes- $2^{a}$ ed. -Campinas, SP: Papirus, 1987. (Coleção Educar Aprendendo - Série Educando).

- Educação sexual da criança: subsidios teóricos e propostas práticas para uma abordagem da sexualidade para além da transversalidade/ César Nunes, Edna Silva. - Campinas, SP: Autores Associados, 2000. - (Coleção Polêmicas de nosso Tempo; 72). 
Filosofia, Sexualidade e Educação: As relações entre os pressupostos éticosociais e histórico-culturais presentes nas abordagens institucionais sobre a educação sexual escolar. Tese de Doutoramento em Educação Unicamp, 1996.

REICH, Wilhen. A revolução sexual. $4^{a}$ ed. Rio de Janeiro: Zahar, 1977. 